\title{
Avaliação da onda $b$ do eletrorretinograma na Athene cunicularia
}

\section{Evaluation of the b-wave electroretinogram in Athene cunicularia}

Márcio Penha Morterá Rodrigues', Adalmir Morterá Dantas²

\section{ResUMO}

Objetivo: Avaliar a onda $b$ do eletrorretinograma da coruja buraqueira (Athene cunicularia), diferenciando a resposta elétrica retiniana em ambiente fotópico e escotópico. Métodos: Foi realizado estudo observacional transversal, com o registro do eletrorretinograma full field de quatorze olhos, sendo sete estimulados em ambiente fotópico e sete em ambiente escotópico sob estímulo com luz branca seguindo protocolo da ISCEV. Resultados: As respostas elétricas da retina da espécie estudada para o espectro de luz aplicado mostraram-se presentes em ambos ambientes, não havendo diferença estatisticamente significativa da resposta elétrica da retina da Athene cunicularia quando estimulada com luz branca, tanto em ambiente escotópico quanto fotópico. Conclusão: Os dados nos permitem, portanto, inferir que a percepção pela Athene cunicularia da cor branca é a mesma, no claro e no escuro, o que pode ser responsável pela capacidade adaptativa da espécie no seu habitat natural.

Descritores: Estrigiformes; Eletrorretinografia; Retina; Aves; Visão;Adaptação ocular

\footnotetext{
'Pós-graduando (doutorado) pela Universidade Federal do Rio de Janeiro; Médico do Serviço de Oftalmologia do Hospital Universitário Clementino Fraga Filho da Universidade Federal do Rio de Janeiro - UFRJ - Rio de Janeiro (RJ), Brasil;

2Professor titular de Oftalmologia da Universidade Federal do Rio de Janeiro - UFRJ - Rio de Janeiro (RJ), Brasil.

Instituição de Realização do trabalho: Hospital Universitário Clementino Fraga Filho

Recebido para publicação em: 19/8/2008 - Aceito para publicação em 1/12/2008
} 


\section{INTRODUÇÃO}

$A$ atividade elétrica retiniana corresponde ao evento inicial do processamento da informação visual. Todas as espécies possuidoras de aparelho visual funcional apresentam alguma resposta deste tipo, de forma que o estudo comparativo entre diferentes espécies nos permite adquirir conhecimentos, previamente desconhecidos, que podem ser aplicados no nosso cotidiano.

Sendo as aves de rapina seres de aguçada capacidade visual e apresentarem estrutura retiniana complexa, tornam-se vertebrados, no mínimo, interessantes para investigação do funcionamento de seu aparato visual, motivo que estimulou o estudo da espécie, Athene cunicularia (coruja buraqueira).

É cediço que estas aves apresentam circuito celular retiniano extremamente organizado e complexo, com presença eventual de duas fóveas ${ }^{(1-4)}$. A retina da espécie estudada possui todas as células e camadas presentes nos vetebrados em geral, se diferenciando por grande concentração de fotorreceptores na fóvea, incluindo bastonetes, contribuindo para a máxima resolução óptica desta região ${ }^{(5)}$.

A espécie em questão possui hábitos de caça crepusculares e descrições histológicas prévias apontam segmentos externos dos bastonetes, longos, motivo que tenta justificar seu hábito crepuscular. Sabe-se que a retina destas aves projeta-se no tálamo e no tecto óptico ${ }^{(5-9)}$.

A discriminação de cores em corujas foi relatada, embora o comprimento de onda da luz não seja importante para o comportamento da ave ${ }^{(10)}$. Embora, a visão das corujas não seja tão sensível quanto se imaginava, as mesmas apresentam vantagens em relação às espécies diurnas em baixos níveis de luminosidade ${ }^{(11)}$. Sua visão serve para a determinação da orientação espacial, distância e velocidade de vôo ${ }^{(12)}$.

O presente trabalho enaltece a coruja buraqueira em virtude de documentação histológica prévia de seus fotorreceptores, motivo pelo qual resolveu-se estudar a sua resposta eletrorretinográfica.

Com o intuito de estabelecer o padrão eletrorretinográfico da espécie e relatar o padrão elétrico da retina em ambiente fotópico e escotópico, decidimos avaliar a atividade elétrica da retina da Athene cunicularia, examinando em especial a onda $b$ do eletrorretinograma.

\section{Métodos}

Foram avaliadas sete corujas da espécie Athene cunicularia, de ambos os sexos, cedidas pelo Instituto Brasileiro do Meio Ambiente e dos Recursos Naturais
Renováveis (IBAMA). Os animais tinham peso compreendido entre 180 e $205 \mathrm{~g}$, altura entre 21,8 e $26 \mathrm{~cm}$ e envergadura de 51 a $60 \mathrm{~cm}$.

O protocolo de pesquisa está em conformidade com o exigido pelo Comitê de Ética para uso de Animais de Laboratório em Pesquisa, Ensino e Extensão (CEPAL) da Faculdade de Medicina do Centro de Ciências da Saúde, Universidade Federal do Rio de Janeiro e pelo IBAMA que através da Portaria ${ }^{\circ} 332$, de 13 de março de 1990, e com base na lei $n^{\circ} 7.735$ de 22 de fevereiro de 1989, artigo 83, XIV do Regimento Interno, aprovado pela Portaria/MINTER n ${ }^{\circ} 445$ de 16 de agosto de 1989 , e tendo em vista o disposto no artigo 14 e seus parágrafos da lei n ${ }^{\circ} 5.197$, de 03 de janeiro de 1967, autorizou a utilização da espécie em questão.

O projeto foi registrado pelo IBAMA1 sob $\mathrm{n}^{\circ}$ 02022.000518/2005-33 e possui ${ }^{\circ}$ de licença para captura/coleta/transporte/exposição 025/05 - RJ.

Os animais selecionados foram submetidos primeiramente à oftalmoscopia direta, seguida de exame de eletrofisiologia ocular, o eletrorretinograma. Para a realização desse exame, os indivíduos da pesquisa foram sedados com sulfato de quetamina $(20 \mathrm{mg} / \mathrm{Kg})$ por via intramuscular; foi obtida midríase com tropicamida tópica $1 \%$, num total de nove microgotas por olho e receberam anestesia local tópica corneana com cloridrato de oxibuprocaína $0,4 \%$ na dose de nove microgotas por olho.Após os procedimentos de anestesia e sedação, três eletrodos em forma de agulha $13 \times 4,5 \mathrm{~mm}$ foram utilizados na realização do exame. Um dos eletrodos foi introduzido no estroma corneano, gerando uma lesão autoselante, sem necessidade de suturas ou curativos; os outros dois introduzidos no subcutâneo, sendo um superiormente e entre os olhos do animal (eletrodo terra) e o outro (eletrodo referência) na região supra-orbitária do olho a ser examinado.

Dos quatorze olhos estimulados, sete foram destinados ao estímulo em ambiente escotópico e sete em ambiente fotópico. Essa decisão foi tomada devido ao possível estresse causado no olho examinado, à dificuldade de se manter o eletrodo fixado na córnea, ao receio da interferência de um edema corneano causado pelo eletrodo, e pela escolha de um olho "virgem de exame" para um melhor registro eletrorretinográfico. A documentação escotópica foi obtida dos olhos esquerdos e a fotópica dos olhos direitos, sendo essa escolha determinada aleatoriamente.

O aparelho de eletrorretinografia utilizado foi o Neuropack II ${ }^{\varpi}$, da empresa Nihon Koden ${ }^{\varpi}$. O flash de luz utilizado foi único e emitido por um estimulador situado a trinta centímetros do olho estimulado tanto 
em ambiente fotópico quanto escotópico tendo como intensidade, 20 Joules.

O estímulo luminoso utilizado compreende o espectro de luz branca, sendo executado após 20 minutos de adaptação ao escuro e 10 minutos ao claro para avaliação em ambiente escotópico e fotópico, respectivamente ${ }^{(13)}$. A ordem de registro respeitada foi estímulo fotópico, seguido de escotópico.

Os parâmetros utilizados para o registro do eletrorretinograma seguiram o protocolo definido pela Sociedade Internacional de Eletrofisiologia Visual Clínica (ISCEV) de 2004, com exceção da utilização da cúpula de Ganzfield ( full field), indisponível no Serviço de Oftalmologia da Universidade Federal do Rio de Janeiro. Os eletrodos utilizados eram iguais e possuíam a mesma impedância. A duração do estímulo luminoso foi $<5 \mathrm{~ms}^{(13)}$.

O tipo de estudo utilizado foi o observacional transversal, com a demonstração do eletrorretinograma da Athene cunicularia em ambiente fotópico e escotópico sob estímulo com luz branca.

Para a confecção dos dados obtidos consideraramse as seguintes convenções:

- Amplitude da onda $b$ : distância entre o ponto mais positivo da onda $b$ e o nível do ponto mais negativo do traçado eletrorretinográfico. Unidade em microvolts;

- Tempo de culminação da onda $b$ : distância entre o início do traçado e o ponto mais positivo da onda $b$. Unidade em milissegundos.

Foram calculados para esses parâmetros os valores de média e desvio padrão.

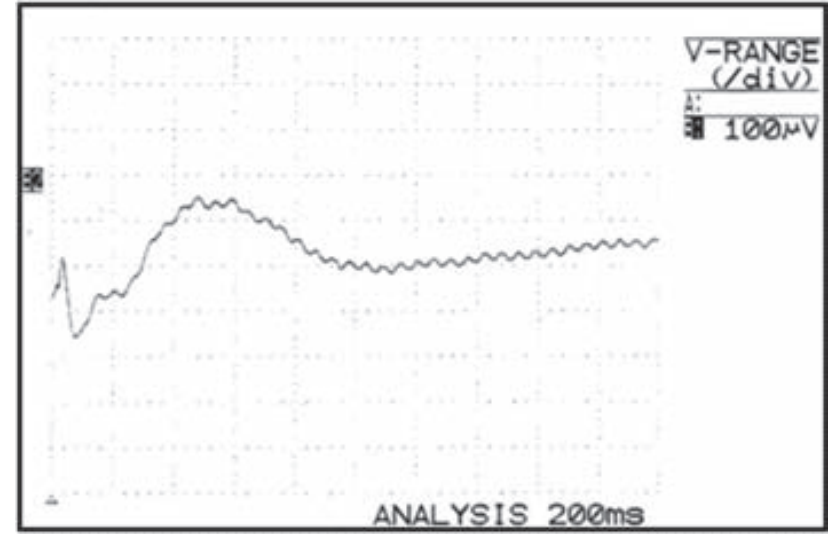

Figura 1: Eletrorretinograma fotópico da Athene cunicularia

Os dados foram analisados utilizando-se o teste t-Student bicaudal emparelhado entre os estímulos, aplicados à mesma variável em ambiente fotópico e escotópico.

\section{Resultados}

Os traçados obtidos em ambos ambientes foram muito semelhantes aos encontrados em seres humanos. $\mathrm{O}$ registro das ondas $a$ e $b$ do eletrorretinograma foi realizado em todas as corujas avaliadas, sendo evidenciados, inclusive, potenciais oscilatórios (Figura 1).

$\mathrm{O}$ anestésico, sulfato de quetamina, foi utilizado na dose preconizada, não havendo intercorrência em decorrência do procedimento anestésico, bem como interferência na reprodutibilidade dos traçados. Os traça-

Tabela 1

Componentes da onda $b$ do eletrorretinograma em ambiente fotópico e escotópico

\begin{tabular}{|c|c|c|c|c|}
\hline \multirow[t]{2}{*}{ Amostra } & \multicolumn{2}{|c|}{ Amplitude $(\mu \mathrm{V})$} & \multicolumn{2}{|c|}{ Tempo de Culminação (ms) } \\
\hline & $\begin{array}{l}\text { Branco } \\
\text { Fotópico }\end{array}$ & $\begin{array}{c}\text { Branco } \\
\text { Escotópico }\end{array}$ & $\begin{array}{c}\text { Branco } \\
\text { Fotópico }\end{array}$ & $\begin{array}{c}\text { Branco } \\
\text { Escotópico }\end{array}$ \\
\hline Coruja 1 & 270,6 & 307 & 60,5 & 48 \\
\hline Coruja 2 & 226 & 273 & 69 & 49,8 \\
\hline Coruja 3 & 246,6 & 387 & 66 & 62,8 \\
\hline Coruja 4 & 213,3 & 228 & 73 & 78 \\
\hline Coruja 5 & 286,6 & 228 & 62,5 & 58 \\
\hline Coruja 6 & 226,6 & 264 & 73 & 49,6 \\
\hline Coruja 7 & 286,6 & 345 & 62 & 61,6 \\
\hline Média & 250,9 & 290,28 & 66,57 & 58,25 \\
\hline Desvio padrão & 30,49 & 59,68 & 5,21 & 10,59 \\
\hline Mínimo & 213,3 & 228 & 60,5 & 48 \\
\hline Máximo & 286,6 & 387 & 73 & 78 \\
\hline
\end{tabular}


dos encontrados não apresentaram alterações no registro final que pudessem ser associados com o anestésico.

Os dados obtidos dos eletrorretinogramas encontram-se na Tabela 1:

Do registro eletrorretinográfico, consideramos para avaliação os valores referentes à Amplitude da onda $b$ e ao Tempo de Culminação da ond $a b$, por serem essas as medidas mais relevantes da literatura.

O teste utilizado, t-Student emparelhado bicaudal foi realizado entre a mesma cor, no caso a cor branca, mesma variável e em ambos ambientes, respeitando como hipótese nula a igualdade entre as condições abaixo mencionadas:

1) Branco - Amplitude - Escotópico x Branco Amplitude-Fotópico;

2) Branco - Tempo de Culminação Escotópico x Branco-Tempo de Culminação-Fotópico.

Após aplicação do teste estatístico, obtivemos com margem de erro de $1 \%$ a informação de que a hipótese nula testada não foi rejeitada.

\section{Discussão}

A estrutura retiniana da Athene cunicularia é bastante semelhante a dos vertebrados em geral, à exceção de algumas peculiaridades bem interessantes, como a presença da fóvea mista. Diferenças estruturais entre retinas de espécies de corujas de hábitos de vida diferentes já foram relatadas e justificadas como decorrência de seu estilo de vida ${ }^{(5-14)}$.

No que tange ao emprego de animais em pesquisa, é relevante mencionar os entraves para a sua realização, devido aos percalços burocráticos de comitês e órgãos responsáveis, que muito dificultam a consecução do estudo; cabe mencionar, entretanto, que a obtenção dos animais via Ibama transcorreu sem intercorrências e foi realizada como preceitua as normas estabelecidas por aquele Instituto.

Quanto ao exame eletrofisiológico, o mesmo foi conduzido sem percalços, como previsto nas normas em vigor. Acreditamos que a utilização do estimulador e não da cúpula de Ganzfield pouco ou nada tenha interferido no resultado final, quando levamos em consideração a estimulação uniforme da retina.

Não ocorreram falhas anestésicas, sendo os animais anestesiados com segurança e com sobrevida pósanestésica de $100 \%$ na amostra estudada.

Os sete animais estudados foram submetidos ao exame eletrofisiológico, tendo sido obtido traçados aproveitáveis em todos os animais.

Do estudo realizado constatamos que a Athene cunicularia responde ao estímulo com luz branca (luz visível), expressando os componentes $a$ e $b$, em ambos os ambientes. Considerando como hipótese nula a igualdade entre os estímulos em ambientes escotópico e fotópico, podemos inferir que não há, do ponto de vista elétrico, diferença estatística entre a resposta elétrica no ambiente fotópico e escotópico.

Essa constatação pode explicar em parte a excepcional visão crepuscular que este animal possui, uma vez que, repita-se, a resposta a esses espectros de luz não se altera em ambientes de diferentes luminosidades.

\section{ConClusão}

A Athene cunicularia apresentou resposta elétrica retiniana ao espectro de cor branco tanto em ambiente fotópico quanto escotópico, não sendo observada distinção estatística entre as respostas encontradas em ambos ambientes.

Os dados encontrados permitem-nos inferir, portanto, que a Athene cunicularia não vislumbra diferença de determinados espectros de luz, no caso o branco, no claro e no escuro, o que pode explicar a excelente visão crepuscular que possui.

No mais, convém destacar que a profunda compreensão da informação visual da espécie em questão deve ser complementada por outras pesquisas mais específicas, igualmente aptas ao integral entendimento da matéria estudada.

\section{Abstract}

Purpose: To evaluate b-wave of the electroretinogram of the burrowing owl (Athene cunicularia), differentiating the retinal electric reply in photopic and scotopic environment. Methods: Transversal observational study was carried through, with the register of the full field electroretinogram of fourteen eyes; seven were stimulated in photopic environment and seven in scotopic environment using with white light according to the ISCEV protocol. Results: The electrical responses of the retina of the species studied showed no statistically significant difference for the applied spectrum of white light in both scotopic photopic environments. Conclusion: The data allow us, therefore, to infer that the perception of the Athene cunicularia of the white color is the same one, in clear and dark environments, what it can be responsible for the adaptive capacity of the species in their natural habitat.

Keywords: Strigiformes; Electroretinography; Retina; Birds;Vision; Adaptation, ocular 


\section{RefERÊNCIAS}

1. Walls GL. Significance of the foveal depression. Arch Ophthalmol. 1937; 18:912-9.

2. Pumphrey RJ. The sense organs of birds. Ibis. 1948; 90(2):171-99.

3. Pumphrey RJ. The theory of the fovea. J Exp Biol. 1948;25(3):299-312.

4. Pumphrey RJ. Sensory Organs: Vision In: Marshall AJ. Biology and comparative physiology of birds. New York (NY): Academic Press; 1961. v.2, p. 55-68.

5. Sales FC. Morfologia dos fotorreceptores da coruja buraqueira (Speotyto cunicularia) [dissertação]. São Paulo: Universidade Federal de São Paulo, 1990.

6. Dice LR. Minimum intensities of illumination under which owls can find dead prey by sight. Am Nat. 1945; 79:385-416.

7. Sillman AJ. The visual pigments of several species of birds. Vision Res. 1969; 9(9):1063-77.

8. Sillman AJ. Avian Vision In: FARNER DS, KING JR. Avian Biology. New York (NY): Academic Press; 1973. v.3, p. 349-87.

9. Bravo H, Pettigrew JD. The distribution of neurons projecting from the retina and visual cortex to the thalamus and tectum opticum of the Barn Owl,Tyto alba, and the Burrowing owl, Speotyto cunicularia. J Comp Neurol. 1981; 199(3):419-41.

10. Martin GR. Color vision in the tawny owl (Strix aluco). J Comp Physiol. Psycol. 1974; 86(1):133-41.
11. Martin GR. Absolute visual threshold and scotopic spectral sensitivity in the tawny owl. Strix aluco. Nature. 1977; 268(5621): 636-8.

12. Erker HG. Die [Bedeutung des Lichtsinnes für aktivität und Raumorientatierung der Schleiereule (Tyto alba guttata Brehm)]. Z Vergl Physiol 1969; 64:37-70. German.

13. Marmor MF, Holder GE, Seelinger MW, Yamamoto S, International Society for Clinical Electrophysiology of Vision. Standard for clinical electroretinography (2004 update). Doc Ophthalmol. 2004; 108(10):107-14.

14. Roze M, Luccciani A, Auphan M. L.' oeil des rapaces Approche électrorétinographique et histologique. Ophthalmologie. 1990; 4(1):64-8.

\section{ENDEREÇO PARA CORRESPONDÊNCIA}

\section{Márcio Penha Morterá Rodrigues}

Hospital Universitário Clementino Fraga Filho

Dept. de Otorrino e Oftalmologia - bloco F - sala 14

Av. Brigadeiro Trompowsky, s/no - 11 ${ }^{\circ}$ andar

CEP 21941-590 - Rio de Janeiro - RJ

Fax: (21) 25900846

E-mail: mortera@uol.com.br 